\title{
NOVOS OLHARES SOBRE O SUJEITO QUE ADOECE NO TRABALHO HOSPITALAR
}

\author{
Silmar Maria Silva ${ }^{1}$, Patrícia Campos Pavan Baptista ${ }^{2}$
}

RESUMO: Este artigo tem como objetivo refletir as novas maneiras de olhar para os sujeitos que adoecem no trabalho hospitalar, evidenciando a potencialidade da pesquisa qualitativa fenomenológica para compreender não apenas a doença, e sim, o sujeito que adoece. $\mathrm{O}$ adoecer no trabalho hospitalar tem se revelado um fenômeno complexo necessitando de estudos que contemplem diversos aspectos, e que possam compreender o cotidiano das relações de trabalho, e as experiências dos sujeitos que adoecem. Despertar para o impacto do adoecimento no trabalho, valorizando o sujeito e a experiência vivida significa o delineamento de novas maneiras de intervir sobre a saúde do trabalhador, minimizando os agravos e compreendendo o trabalhador em sua totalidade existencial.

DESCRITORES: Pesquisa qualitativa; Saúde do trabalhador; Recursos humanos em hospital.

\section{NEW PERSPECTIVES ON SUBJECTS WHO BECOME ILL IN HOSPITAL WORK}

ABSTRACT: This article aims to reflect on the new ways of viewing those subjects who become ill in hospital work, evidencing qualitative phenomenological research's potential for understanding not only the illness, but also the subject who falls ill. Falling ill in hospital work has been shown to be a complex phenomenon, requiring studies which consider diverse aspects and which can understand the everyday of work relationships and the experiences of the subjects who become ill. Becoming aware of the impact of becoming ill at work and valuing the subject and the experience lived through means delineating new ways of intervening in the worker's health, minimizing harm and understanding the worker in his or her existential totality.

DESCRIPTORS: Qualitative research; Worker's health; Human resources in hospital.

\section{NUEVAS MIRADAS SOBRE EL SUJETO QUE ADOLECE EN EL TRABAJO HOSPITALAR}

RESUMEN: Este artículo tiene como objetivo reflexionar sobre nuevas formas de mirar para los sujetos que adolecen en el trabajo hospitalar, evidenciando la potencialidad de la investigación cualitativa fenomenológica para comprender no solo la enfermedad, pero el sujeto que adolece. El adolecer en el trabajo hospitalar viene se revelando un fenómeno complejo necesitando de estudios que contemplen diversos aspectos, y que puedan comprender el cotidiano de las relaciones de trabajo, y las experiencias de los sujetos que adolecen. Despertar para el impacto del adolecer en el trabajo, valorando el sujeto y su experiencia significa la delineación de nuevas formas de intervenir en la salud del trabajador, minimizando los agravios y comprendiendo el trabajador en su totalidad existencial.

DESCRIPTORES: Investigación cualitativa; Salud del trabajador; Recursos humanos en hospital.

${ }^{1}$ Enfermeira. Doutoranda pelo Programa de Pós-Graduação em Gerenciamento em Enfermagem da Escola de Enfermagem da Universidade de São Paulo - EE USP.

${ }^{2}$ Enfermeira. Professora Doutora do Departamento de Orientação Profissional da EE USP.

Autor correspondente: 


\section{INTRODUÇÃO}

O trabalho está intimamente relacionado à vida do ser humano, pois pode determinar a forma que o homem se relaciona com o mundo, uma vez que é por meio do trabalho que se insere na sociedade, podendo ser entendido como sua identidade social. Além disso, o trabalho carrega em si um duplo papel, pois ao mesmo tempo em que pode proporcionar o desenvolvimento pessoal, a possibilidade de adquirir bens materiais, valorização pessoal e profissional, quando realizado sob condições inadequadas pode gerar prejuízo à saúde, desencadear doenças, reduzir a expectativa de vida e até mesmo levar à morte ${ }^{(1-2)}$.

Embora o trabalho seja favorável ao possibilitar a integração social, o gregarismo humano e a formação de uma identidade pessoal e social vêm sendo modificados globalmente pelas constantes exigências do mundo atual, chamando a atenção questões referentes à redução da força de trabalho, ao ritmo de trabalho intensificado e à precarização do trabalho ${ }^{(3)}$. Esses fatores têm gerado conflitos entre as metas organizacionais e as necessidades dos trabalhadores, o que dá ao trabalho atributos de um grande agente estressor e desencadeante de acidentes, adoecimentos e mortes ${ }^{(4)}$.

As transformações no campo do trabalho têm determinado novos processos de adoecimento no traba1ho, configurando alterações no perfil epidemiológico das doenças. Observa-se o agravamento de algumas doenças, como o aumento da prevalência daquelas relacionadas ao trabalho, como os Distúrbios Osteomusculares Relacionados ao Trabalho (DORT) e o surgimento de novas formas de adoecimento, como o estresse e a fadiga física e mental ${ }^{(5-6)}$.

Portanto, também o adoecer do trabalhador hospitalar é permeado por diversos fatores que necessitam ser analisados para o seu entendimento, principalmente sob a ótica de quem adoece, exigindo perspectivas diferentes e complementares para sua compreensão, assim como transcender o positivismo e a visão reducionista do processo de adoecer.

Considerando os aspectos descritos anteriormente, o presente estudo tem como objetivo refletir sobre um novo olhar para os trabalhadores que adoecem no trabalho, especialmente na área hospitalar, descrevendo a importância e os avanços da utilização do referencial da pesquisa qualitativa fenomenológica como um método aplicado aos estudos de saúde do trabalhador.

\section{A FENOMENOLOGIA E O ADOECIMENTO NO TRABALHO HOSPITALAR}

O aprofundamento teórico em saúde do trabalhador revela que os estudos com abordagem compreensiva têm aumentado, ainda que de modo lento, vislumbrando novos caminhos na assistência à saúde do trabalhador $^{(7)}$. Considerando as abordagens compreensivas, destaca-se a Fenomenologia, que consiste no estudo dos significados articulados no discurso do sujeito no qual o fenômeno é desvelado, ou seja, o enfoque fenomenológico valoriza o ser em sua singularidade e busca compreender a experiência vivida pelo sujeito e as estruturas onde o fenômeno ocorre.

Como movimento filosófico, a Fenomenologia nasce no início do século XX com a obra Investigações Lógicas, de Edmund Husserl (1859-1938). O termo fenomenologia deriva das palavras gregas: phainomenon (aquilo que se mostra a partir de si mesmo) e logos (ciência ou estudo). Assim, Fenomenologia é o estudo ou a ciência do fenômeno e fenômeno significa trazer à luz, colocar sob iluminação, mostrar-se a si mesmo em si mesmo. Desta forma, fenomenologia é a volta às próprias $\operatorname{coisas}^{(8)}$.

A Fenomenologia convoca a retomar o caminho qualitativo da existência e recuperar o sentido do ser, da existência humana no mundo. Enquanto método de pesquisa é um modo de abordar o fenômeno, através da apreensão da sua essência. Portanto, a Fenomenologia pode ser considerada como o estudo das essências, permitindo o retorno ao mundo vivido, ao mundo da experiência, destituindo-se de preconceitos ou crenças, valorizando a descrição da experiência vivenciada pelo sujeito, uma vez que os fenômenos não podem ser compreendidos isolados do sujeito que os vive ${ }^{(9-10)}$.

O ponto de partida é voltar às próprias coisas, segundo o programa husserliano de transcender as representações espontâneas do senso comum, onde o primeiro passo é reconhecer a prioridade da prática, da esfera do fazer e agir, sobre o pensamento e a reflexão. A experiência não se resume à capacidade humana de representar o mundo por meio de processos cognitivos, pois guarda em si mesma, as significações. Assim, para a Fenomenologia, a operação primordial de significação é que o expresso não existe separadamente da expressão. E, como tal, é encarnada, ou seja, é um fenômeno sensível ao corpo e não uma mera questão de subjetividade. Nesse aspecto, o Método Fenomenológico está voltado para apreender as significações na medida em que são simplesmente dadas e tal como 
são dadas pelas nossas experiências, preocupando-se com o solo originário do sentido ${ }^{(11)}$.

Nesse sentido, a vivência de um acidente ou doença relacionada ao trabalho geralmente impõe alterações físicas e limitações ao trabalhador, que enquanto ser, único e singular constrói seu modo particular de conviver com o adoecimento e enfrentar as dificuldades impostas no seu cotidiano, reelaborando o sentido de sua vida.

Nestes termos, a pessoa doente deve recriar, tratar de dar sentido à sua experiência, extraindo dela a parte positiva. A vivência da doença altera profundamente $o$ plano afetivo e relacional influenciando as relações do sujeito que adoece com o mundo, uma vez que o olhar da pessoa que está doente e sofre é um olhar cheio de significado, mas somente se apercebe disso quem observa e se mostra receptivo à dor ${ }^{(12)}$.

No cotidiano hospitalar os trabalhadores estabelecem relações com inúmeros profissionais, no entanto, o vínculo mais expressivo do seu trabalho se dá por meio da assistência ao paciente. É importante destacar que o processo de cuidar sofre influência à medida que o sujeito que está cuidando adoece. Ao mesmo tempo, o ambiente hospitalar tem favorecido o adoecimento destes trabalhadores ao proporcionar a exposição às cargas de trabalho devido ao processo e condições de trabalho, caracterizado por situações conflitantes, sobrecarga de atividades, número insuficiente de recursos humanos, ritmo acelerado e tarefas superpostas e repetitivas, gerando repercussões físicas e mentais ${ }^{(13)}$.

Logo, o trabalho hospitalar está permeado de fatores que podem interferir na saúde dos trabalhadores, ocasionando acidentes, doenças e incapacidade temporária ou permanente, os quais devem ser investigados não apenas por meio das taxas e indicadores de processo saúde- doença, mas a partir de uma compreensão aprofundada sobre o sujeito que adoece cuidando de quem está doente ${ }^{(7)}$.

Os traços fenomenológicos do sofrimento humano têm sido analisados por vários pensadores e, atualmente, as pesquisas com a abordagem fenomenológica têm contribuído para a nossa ação profissional, sobretudo para uma compreensão do ser, para uma aproximação das experiências vividas e construção de estratégias que possam alterar os perfis de adoecimento no trabalho hospitalar. Assim, a Fenomenologia convida a repensar na existência do ser, revendo os significados atribuídos à saúde, ao adoecimento e às limitações, considerando que nos momentos de maior fragilidade, o ser humano pode resgatar o seu projeto de ser-si-mesmo ou abandoná-lo, recusando as possibilidades que a existência humana lhe reserva ${ }^{(7)}$.
Notáveis contribuições para o conhecimento fenomenológico têm sido descritas ao longo das últimas décadas, evidenciando a sua importância para descrever os fenômenos relativos ao processo saúde-doença por meio dos sujeitos, possibilitando a elaboração de novas estratégias de intervenção e o redirecionamento de práticas assistências à saúde ${ }^{(14-16)}$.

\section{CONSIDERAÇÕES FINAIS}

O adoecimento no trabalho hospitalar é um fenômeno complexo, permeado por vivências e significações. Assim, ao refletir sobre as novas maneiras de olhar para os sujeitos que adoecem no trabalho hospitalar, evidencia-se que a pesquisa qualitativa de abordagem fenomenológica pode fornecer subsídios para compreender o mundo-vivido destes trabalhadores. Este conhecimento permite um repensar sobre o processo de trabalho e suas inter-relações, vislumbrando caminhos para uma reabilitação e manutenção da qualidade de vida no trabalho.

Despertar para o impacto do adoecimento no trabalho, valorizando o sujeito e a experiência vivida significa o delineamento de novas maneiras de intervir sobre a saúde do trabalhador, minimizando os agravos e compreendendo o trabalhador em sua totalidade existencial.

\section{REFERÊNCIAS}

1. Sanches EN, Cutolo LRA, Soares P, Silva RM. Organização do trabalho, sintomatologia dolorosa e significado de ser portador de LER/DORT. Psicol. Argum. 2010;28(63):313-24.

2. Poersch AL, Ramos MZ, Silva RN. Reabilitação profissional: o coletivo como ferramenta de resignificação. Psico. 2010;41(1):137-43.

3. Felli VEA, Tronchin DMR. A qualidade de vida no trabalho e a saúde do trabalhador de enfermagem. In: Kurcgant P. Gerenciamento em enfermagem. $2^{\mathrm{a}}$ ed. Rio de Janeiro: Guanabara-Koogan; 2010. p. 85-103.

4. Campos JF, David HSL. Avaliação do contexto de trabalho em terapia intensiva sob o olhar da psicodinâmica do trabalho. Rev Esc Enferm USP. 2011;45(2):363-8.

5. Toldrá RC, Daldon MTB, Santos MC, Lancman S. Facilitadores e barreiras para o retorno ao trabalho: a experiência de trabalhadores atendidos em um Centro 
de Referência em Saúde do Trabalhador - SP, Brasil. Rev. bras. saúde ocup. 2010;35(121):10-22.

6. Giomo DB, Freitas FCT, Alves LA, Robazzi MAC. Acidentes de trabalho, riscos ocupacionais e absenteísmo entre trabalhadores de enfermagem hospitalar. Rev. enferm. UERJ. 2009;17(1): 24-29.

7. Baptista PCP, Merighi MAB, Silva A. Angústia de mulheres trabalhadoras de enfermagem que adoecem por distúrbios osteomusculares relacionados ao trabalho. Rev Bras Enferm. 2011;64(3): 438-44.

8. Figueroa CG. La psicología fenomenológica de Husserl y la psicopatologia. Rev chil. neuro-psiquiat. 2008;46(3):224-37.

9. Carvalho MDB, Valle ERM. A pesquisa fenomenológica e a enfermagem. Acta Scientiarum. Biological Sciences. 2002;24(3):843-7.

10. Merighi MAB, Praça NS. Abordagens teóricometodológicas qualitativas. A vivência da mulher no período reprodutivo. Rio de Janeiro: Guanabara Koogan; 2003.

11. Alves PC. A Fenomenologia e as abordagens sistêmicas nos estudos sócio-antropológicos da doença: breve revisão crítica. Cad. Saúde Pública. 2006;22(8):1547-54.

12. Roselló FT. Antropologia do cuidar. Petrópolis: Vozes; 2009.

13. Spindola T, Martins ER. O estresse e a enfermagem: a percepção das auxiliares de enfermagem de uma instituição pública. Esc. Anna Nery. 2007;11(2):212-9.

14. Merighi MAB, Jesus MCP, Domingos SRF, Oliveira DM, Baptista PCP. Ser docente de enfermagem, mulher e mãe: desvelando a vivência sob a luz da Fenomenologia Social. Rev. Latino-Am. Enfermagem. 2011;19(1):164-70.

15. Salomé GM, Espósito VHC. Vivências de acadêmicos de enfermagem durante o cuidado prestado às pessoas com feridas. Rev Bras Enferm. 2008;61(6):822-7.

16. Duarte MR, Rocha SS. As contribuições da filosofia heideggeriana nas pesquisas sobre o cuidado em enfermagem. Cogitare enferm. 2011;16(2):361-4. 